\section{Cureus}

Received 10/26/2015

Review began 11/08/2015

Review ended 12/30/2015

Published 01/05/2016

\section{C) Copyright 2016}

Arnas-Leon et al. This is an open access article distributed under the terms of the Creative Commons Attribution License CC-BY 3.0., which permits unrestricted use, distribution, and reproduction in any medium, provided the original author and source are credited.

\title{
Complete Remission in Metastatic Pheochromocytoma Treated with Extensive Surgery
}

Claudia Arnas-Leon ${ }^{1}$, Víctor Sánchez ${ }^{2}$, Ana D. Santana Suárez ${ }^{1}$, Sara Quintana Arroyo ${ }^{1}$, Carmen Acosta ${ }^{1}$, Francisco Javier Martinez Martin ${ }^{3}$

1. Endocrinology and Nutrition, Hospital Universitario de Gran Canaria Doctor Negrín 2. Radiology, Hospital Universitario de Gran Canaria Doctor Negrín 3. Endocrinology, Clinica San Roque

$\square$ Corresponding author: Claudia Arnas-Leon, claudia.al1988@gmail.com Disclosures can be found in Additional Information at the end of the article

\section{Abstract}

Pheochromocytomas are rare neuroendocrine tumors that arise from chromaffin cells of the adrenal medulla. Malignant pheochromocytoma is defined as the presence of metastatic spread in tissues where chromaffin cells are not usually present. This case report describes the case of a relapsed malignant pheochromocytoma, spread to the right liver lobe, superior pole of the right kidney, posterior right hemidiaphragm, right hemidiaphragmatic pillar, inferior vena cava, and regional lymph nodes. After evaluation, an extensive surgery was performed, with resection of all the affected tissues and regional lymphadenectomy. No adjuvant treatment (radiotherapy or chemotherapy) was given. Complete clinical, biochemical, and radiological remission was achieved, with normalisation of metanephrine and normetanephrine. To date, six years after surgery, the patient remains asymptomatic and normotensive without taking any antihypertensive medication. We conclude that the therapeutic approach should be individualized in the case of metastatic pheochromocytoma. Extensive surgery can be considered as a treatment option, even in the case of multiple metastases, as it may be able to achieve complete remission of the disease, avoiding costly and potentially dangerous adjuvant therapies.

Categories: Endocrinology/Diabetes/Metabolism, General Surgery, Oncology

Keywords: pheochromocytoma, metastatic pheochromocytoma, malignant pheochromocytoma, metanephrines, normetanephrines, extensive surgery, catecholamines

\section{Introduction}

Pheochromocytomas are rare catecholamine-secreting tumors of the adrenal medulla, with an estimated annual incidence of 8 per 100,000 person-years. The prevalence is increasing due to advanced imaging tests with a high rate of incidental adrenal mass [1].

Classic clinical presentation of pheochromocytoma consists of headache, sweating, flushing or pallor, and episodes of paroxysmal hypertension and tachycardia. Less frequent symptoms are orthostatic hypotension, hyperglycemia, and cardiomyopathy. The patient might be asymptomatic as well [2]. Thus, the main associated morbidity and mortality remains on the difficult management of hypertensive crisis. In the worst scenario, cardiovascular complications and eventually death may occur (myocardial infarction, heart failure, or stroke).

The diagnosis is typically confirmed by measurements of urinary and plasma fractionated 
metanephrines and catecholamines [3]. After the biochemical confirmation, a radiological evaluation should be performed to locate the tumor. Abdominal computer tomography (CT) scan and magnetic resonance imaging (MRI) are the standard imaging tests, but ${ }^{131}$ I-MIBG is particularly useful in confirming the functionality of the tumor and also in locating metastatic disease or extra-adrenal primary tumors (paragangliomas). Almost 95\% of the tumors are inside the abdomen and pelvis [4].

Although there are different treatment options, laparoscopic resection is considered the firstline therapy option, because total resection ensures the best chance of complete remission on a potentially lethal disease [5]. It is necessary to spotlight the importance of adequate blocking of the alpha adrenergic receptors with intravenous or oral medication, before and during the surgery, to avoid perioperative complications. Other treatment options are radiotherapy for bone injury, ${ }^{131}$ I-MIBG for unresectable malignant pheochromocytomas, or chemotherapy with cyclophosphamide for metastatic disease [6].

According to the 2004 World Health Organization (WHO) criteria, a pheochromocytoma should be considered as malignant if metastatic spread exists [7]. Metastatic disease in pheochromocytoma is infrequent (5-26\%) and may be present on the initial diagnosis or after surgical removal. Most treatments are palliative in these cases, and without treatment, the survival is less than $50 \%$ in five years [8].

\section{Case Presentation}

We present the case of a 58-year-old female patient with an unremarkable personal history of chronic diseases, except colonic and sigmoid diverticulosis. The patient denied any headache or palpitations and took no medications. The physical examination revealed mild hypertension $(150 / 90 \mathrm{mmHg})$ and tachycardia $(100 \mathrm{bpm})$ without any other pathological findings. Informed patient consent was obtained.

During a hospital admission for acute diverticulitis, an abdominal CT scan was performed. An incidental solid adrenal mass of $8 \times 5.5 \times 9 \mathrm{~cm}$ was found on the right adrenal gland with extension to the right lobe of the liver and compression of the inferior vena cava and collateral perirenal circulation. A right adrenalectomy was carried out without postsurgical complications, with an anatomopathological final diagnosis of pheochromocytoma.

Twelve years later, a control abdominal CT scan showed a 9 x $4.5 \mathrm{~cm}$ irregular and heterogeneous mass in the surgical area with poorly defined outlines, which had spread to the right lobe of the liver, the superior pole of the right kidney, the posterior right hemidiaphragm and right hemidiaphragmatic pillar, and the inferior vena cava, demonstrating metastatic recurrence of a malignant pheochromocytoma (as seen in the abdominal CT in Figure 1 and abdominal MRI in Figure 2). 


\section{Cureus}

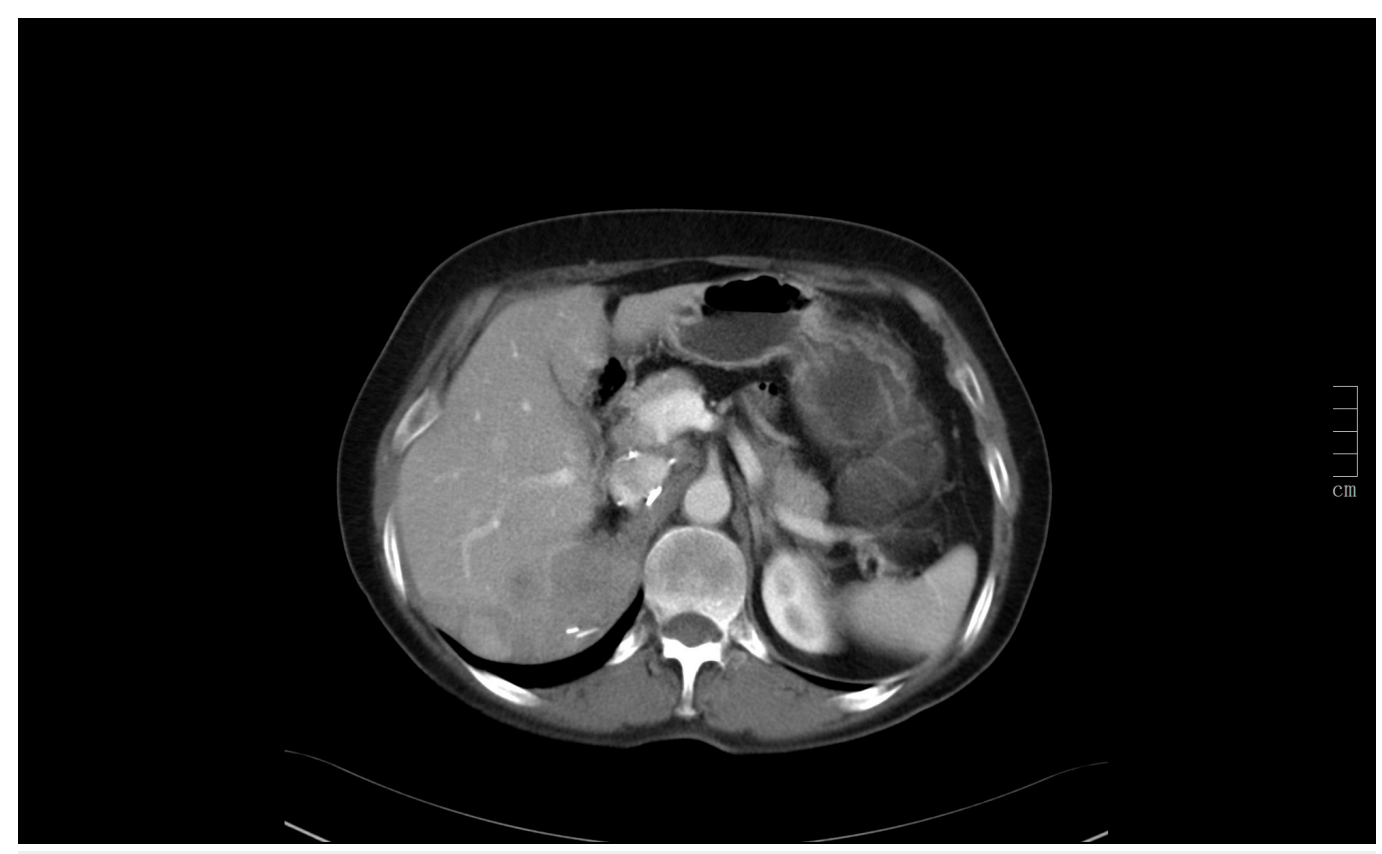

FIGURE 1: Metastatic spread of pheochromocytoma in abdominal CT

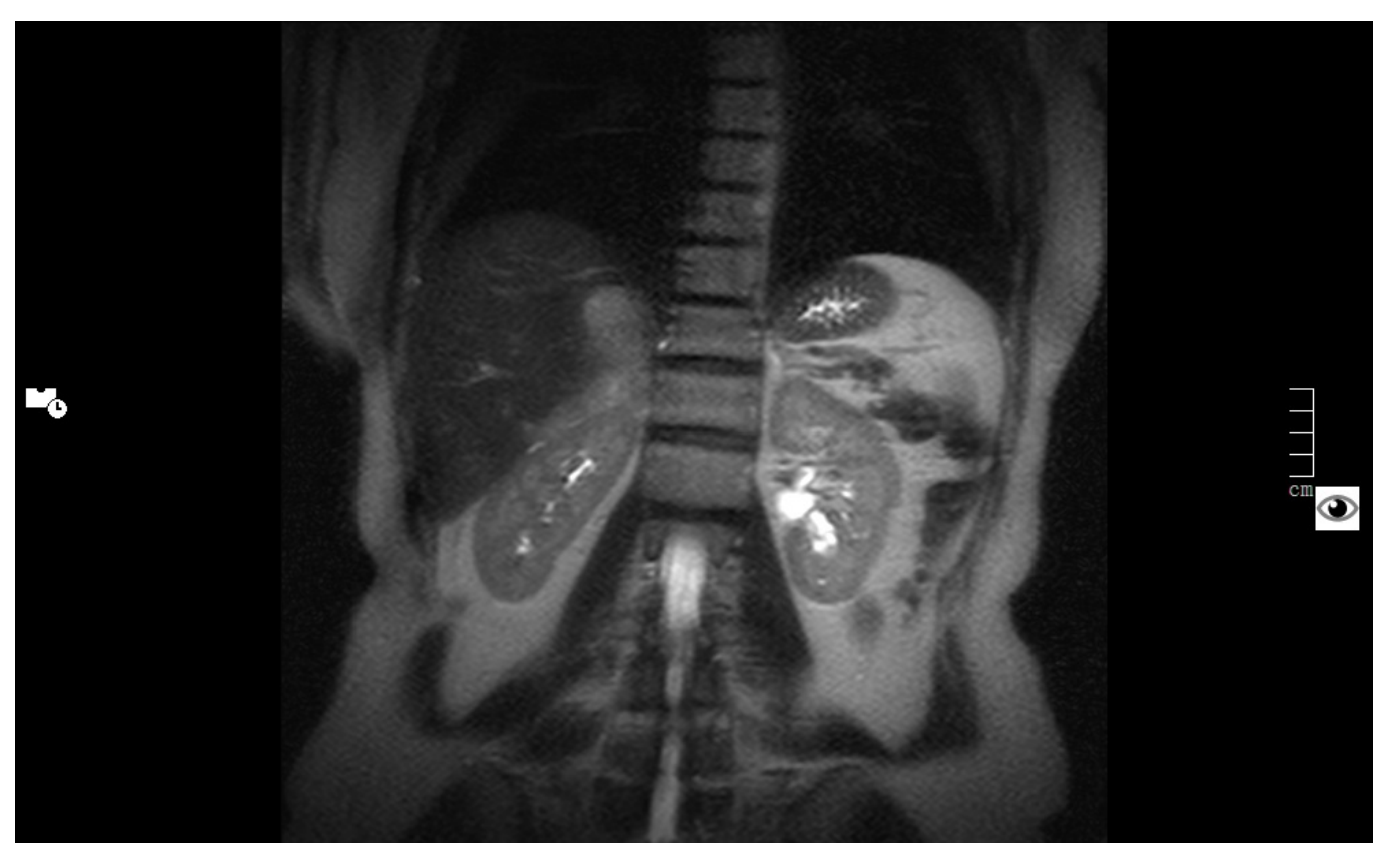

FIGURE 2: Metastatic spread of pheochromocytoma in right liver lobe, right kidney, and right hemidiaphragm in abdominal MRI

The patient denied abdominal pain and remained asymptomatic. At this point, the patient was referred to our Hypertension Clinic. 


\section{Cureus}

Lab tests showed routine blood chemistries and $\mathrm{CBC}$ without any relevant findings, except for increased catecholamines: serum metanephrine $>1.200 \mathrm{pg} / \mathrm{ml}(0-90)$, serum normetanephrine $>1.600 \mathrm{pg} / \mathrm{ml}(0-180)$, urine metanephrine $23.264 \mathrm{ug} / 24 \mathrm{~h}$ (52-341), urine normetanephrine $18.915 \mathrm{ug} / 24 \mathrm{~h}$ (88-444), serum adrenalin $302 \mathrm{pg} / \mathrm{ml}$ (20-60), serum noradrenalin $995 \mathrm{pg} / \mathrm{ml}$ (135-650), and serum dopamine 33 pg/ml (10-150).

The patient was admitted, and the case was discussed in a multidisciplinary expert committee. An extensive surgery was performed, with a right lobar hepatectomy, right nephrectomy, right hemidiaphragm partial resection, perivascular, and retroperitoneal and right liver lobe lymphadenectomy (as can be seen in the abdominal CT after surgery in Figure 3).

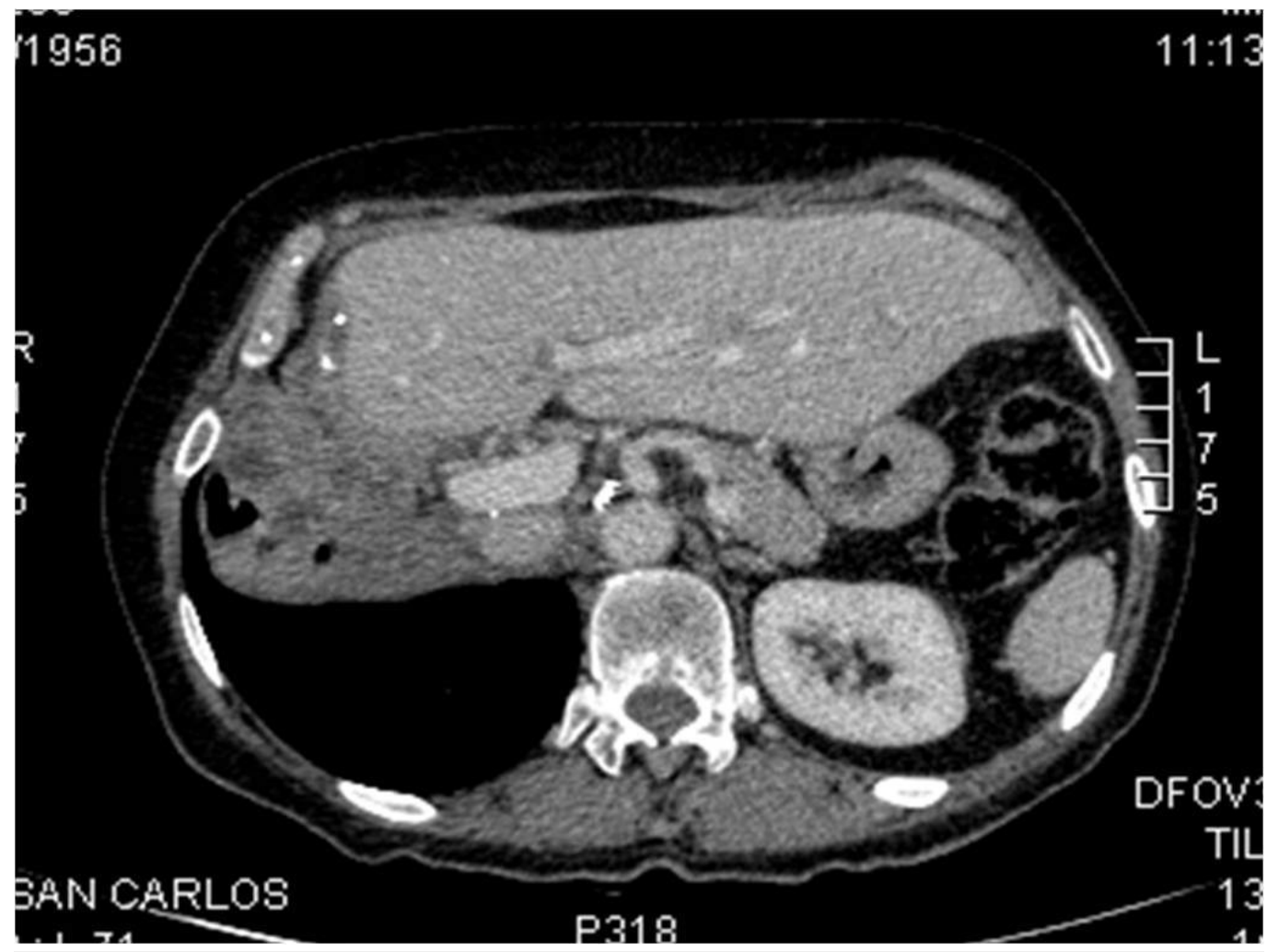

FIGURE 3: Abdominal CT scan after extensive surgery

The intra-surgical biopsy confirmed the diagnosis of metastatic pheochromocytoma. There were no complications during surgery nor in the early and late postsurgical periods. The relapsed pheochromocytoma was entirely resected, and lab tests showed normalisation of the catecholamines. Additional treatment was therefore not required after the extensive surgery.

To date, the patient has been evaluated annually for six years and remains asymptomatic and normotensive without taking any antihypertensive medication. Annual abdominal CT scans and lab tests have revealed no signs of pheochromocytoma complications with metanephrine and normetanephrine levels consistently remaining in the low-normal range (Table 1). 


\section{Cureus}

\begin{tabular}{|c|c|c|c|c|c|c|c|}
\hline & 09/09 & 09/10 & 05/11 & $11 / 12$ & $06 / 13$ & $05 / 14$ & 06/15 \\
\hline Metanephrine (serum) & $>1200 \mathrm{pg} / \mathrm{ml}$ & 30 pg/ml & $72 \mathrm{pg} / \mathrm{ml}$ & 34 pg/ml & 35 pg/ml & 70 pg/ml & $148 \mathrm{pg} / \mathrm{ml}$ \\
\hline Normetanephrine (serum) & $>1600 \mathrm{pg} / \mathrm{ml}$ & $94 \mathrm{pg} / \mathrm{ml}$ & $141 \mathrm{pg} / \mathrm{ml}$ & $113 \mathrm{pg} / \mathrm{ml}$ & $47 \mathrm{pg} / \mathrm{ml}$ & $119 \mathrm{pg} / \mathrm{ml}$ & $137 \mathrm{pg} / \mathrm{ml}$ \\
\hline
\end{tabular}

TABLE 1: Metanephrine and normetanephrine follow-up

\section{Discussion}

Pheochromocytomas are neuroendocrine tumors that arise from chromaffin cells of the adrenal medulla. Only 5-26\% are malignant according to large series, and malignancy requires evidence of metastases and tumor spread in sites where chromaffin tissue is not normally present. Neither the radiologic appearance of the tumor nor its pathology allow for the diagnosis of malignancy [8].

Imaging tests are necessary in order to document tumor spread. The most recommended imaging studies are CT and MRI scans, with a sensitivity of $77-98 \%$ and $90-100 \%$, respectively, and a specificity of $29-92 \%$ and $50-100 \%$, respectively, in the localization of adrenal or extraadrenal tumors [9].

Pheochromocytomas usually enhance avidly on CT scans, and even when they may wash out like adrenal adenomas, these tumors tend to enhance greater in an arterial or portal venous contrast phase. One hundred and ten Hounsfield Units (HU) of enhancement on the arterial phase indicates pheochromocytoma, and metastases typically are hypervascular and radiologically hyperintense. According to scientific literature, the use of contrast may cause hypertensive crisis so it should be used carefully [10].

The most significant property of these tumors on MRI scans is that they are usually shown as hyperintense on T2, which practically confirms a pheochromocytoma [10].

However, metastases or local recurrences may be microscopic at diagnosis and become apparent some years later. This is why it is recommended to perform a yearly follow-up with lab tests that include metanephrines and normetanephrines [8].

Surgery is considered the first line therapeutic option, and it should be considered even in the case of tumor spread. Resection of distant metastases decreases catecholamine secretion and, therefore, reduces the cardiovascular risk factors and, ultimately, the risk of death from cardiovascular complications [8]. All of this contributes to relieve the patient's symptoms, leading to an improved quality of life [9].

In the case of malignant disease, surgery, as the only option of treatment, is rarely curative. The five-year survival rate of these patients varies between $34 \%$ and $60 \%$, mainly depending on the location of the metastatic lesions [9].

Alternatives to surgical resection consist of radiometabolic treatment with ${ }^{131}$ I-MIBG, radiofrequency ablation, external radiotherapy, and use of antineoplastic agents, such as cyclophosphamide, vincristine, and dacarbazine [8]. Unfortunately, none of these therapies usually increase the survival on their own and a combination of them is often needed to get a 
satisfactory result. However, the initial approach with any of these therapy options, especially in the case of chemotherapy, may be useful in order to reduce the tumor size before surgery [9].

\section{Conclusions}

In conclusion, metastatic pheochromocytoma is a rare and challenging disease, and there are several options for treatment, from chemotherapy to surgery. We have presented the case of a female patient affected by an infrequently large malignant pheochromocytoma spread to vital organs with an extraordinary response to extensive surgery who did not require any other additional treatment.

We recommend that an individual approach is needed and extensive surgery should be considered in patients who may benefit from this type of therapy in order to avoid chronic medications with undesirable side effects.

\section{Additional Information \\ Disclosures}

Human subjects: Consent was obtained by all participants in this study. Conflicts of interest: In compliance with the ICMJE uniform disclosure form, all authors declare the following: Payment/services info: All authors have declared that no financial support was received from any organization for the submitted work. Financial relationships: All authors have declared that they have no financial relationships at present or within the previous three years with any organizations that might have an interest in the submitted work. Other relationships: All authors have declared that there are no other relationships or activities that could appear to have influenced the submitted work.

\section{References}

1. Guerrero MA, Schreinemakers JM, Vriens MR, Suh I, Hwang J, Shen WT, Gosnell J, Clark OH, Duh QY: Clinical spectrum of pheochromocytoma. J Am Coll Surg. 2009, 209:727-32. 10.1016/j.jamcollsurg.2009.09.022

2. Kudva YC, Young WF Jr, Thompson GB, Grant CS, van Heerden JA: Adrenal incidentaloma: An important component of the clinical presentation spectrum of benign sporadic adrenal pheochromocytoma. Endocrinologist. 1999, 9:77-84.

3. Sawka AM, Jaeschke R, Singh RJ, Young WF Jr: A comparison of biochemical tests for pheochromocytoma: measurement of fractionated plasma metanephrines compared with the combination of 24-hour urinary metanephrines and catecholamines. J Clin Endocrinol Metab. 2003, 88:553-58. 10.1210/jc.2002-021251

4. Bravo EL: Evolving concepts in the pathophysiology, diagnosis, and treatment of pheochromocytoma. Endocr Rev. 1994, 15:356-68. 10.1210/er.15.3.356

5. Pacak K, Eisenhofer G, Ahlman H, Bornstein SR, Gimenez-Roqueplo AP, Grossman AB, Kimura N, Mannelli M, McNicol AM, Tischler AS; International Symposium on Pheochromocytoma: Pheochromocytoma: recommendations for clinical practice from the First International Symposium. October 2005. Nat Clin Pract Endocrinol Metab. 2007, 3:92102. 10.1038/ncpendmet0396

6. Oleaga A, Goñi G: Pheochromocytoma: diagnostic and therapeutic update (article in English and Spanish). Endocrinol Nutr. 2008, 55:202-16. 10.1016/S1575-0922(08)70669-7

7. World Health Organization: Pathology and Genetics of Tumours of the Endocrine Organs . DeLellis RA, Lloyd RV, Heitz PU, Eng C (ed): IARC Press, Lyon, France; 2004.

8. Eisenhofer G, Bornstein SR, Brouwers FM, Cheung NK, Dahia PL, de Krijger RR, Giordano TJ, Greene LA, Goldstein DS, Lehnert H, Manger WM, Maris JM, Neumann HP, Pacak K, Shulkin BL, Smith DI, Tischler AS, Young WF Jr: Malignant pheochromocytoma: current status and initiatives for future progress. Endocr Relat Cancer. 2004, 11:423-36. 10.1677/erc.1.00829

9. Parenti G, Zampetti B, Rapizzi E, Ercolino T, Giachè V, Mannelli M: Updated and new 


\section{Cureus}

perspectives on diagnosis, prognosis, and therapy of malignant pheochromocytoma/paraganglioma. J Oncol. 2012, 2012:872713. 10.1155/2012/872713

10. Blake MA, Holalkere NS, Boland GW: Imaging techniques for adrenal lesion characterization. Radiol Clin North Am. 2008, 46:65-78. 10.1016/j.rcl.2008.01.003 